\title{
Design of Ship Cabin Leakage Alarm System Based on MCU
}

\author{
Hai-yan Song ${ }^{1, a,{ }^{*}}$, Ji-tao Chen ${ }^{1, b}$, Fu-zhen Qin $^{1, a}$ \\ ${ }^{1}$ Qingdao Huanghai College, Qingdao, Shandong, CHina \\ a705733729@qq.com, b94663067@qq.com.
}

\begin{abstract}
Cabin leakage is a common and serious accident when the ship is sailing. In order to prevent the accident from happening in the bud, the paper designs a sound and light alarm system. The electrode type water immersion sensor is used to combine the water leakage detection and alarm. When the ship is leaking, the sound and light alarm is carried out by a single chip microcomputer, so as to play an early warning role to the danger.
\end{abstract}

Keywords: Ship, Leakage alarm, MCU.

\section{Introduction}

At present, the international multi-channel detection of water leakage for the sound and light alarm systems are relatively confusing. Therefore, it is of great practical significance and application value to design a kind of multi channel sound and light alarm system.

\section{Overall system design}

This system is a multi-channel sound detection system for ship cabin leakage detection. The manual key, the sound alarm and the light alarm in the alarm system are arranged in the monitoring room.

System structure The single channel system block diagram of the cabin leakage multi-channel sound and light alarm system is shown in figure 1. MCU controller STC company's STC12C5A60S2 enhanced $51 \mathrm{MCU}$, built in the 8 Channel 10 bit precision comparison of analog to digital converter, has the advantages of high speed, low power consumption, the input voltage range of $0-5 \mathrm{~V}$. STC12C5A60S2 is the core of the cabin Water Leakage multichannel acousto-optic alarm, it is used as the normal operation of a control system, to deal with the electrode flooding signal sensor, so it is the central element of the whole system.

System function The detection system of multi-channel water leakage can be used to detect the water leakage in the cabin of the cabin at the same time. Through the microcontroller to monitor the sensor, if they detects leakage, the LED light alarm and buzzer sound alarm. After the completion of water leakage or if it is found to be false alarm, the alarm can be turn off through manual intervention .

Hardware circuit design.

Water immersion sensor detection circuit. The circuit uses an electrode type water immersion sensor suitable for a ship and it is placed in a region to be detected. The change of electrode immersion resistance principle determines the state of the sensor based on the voltage detection data, and are compared with numerical processing through the voltage comparator, it gets level external circuit state, and sents to the microcontroller 
STC12C5A60S2 detection processing and storage. The interface circuit of the electrode type water immersion sensor is shown in figure 2.

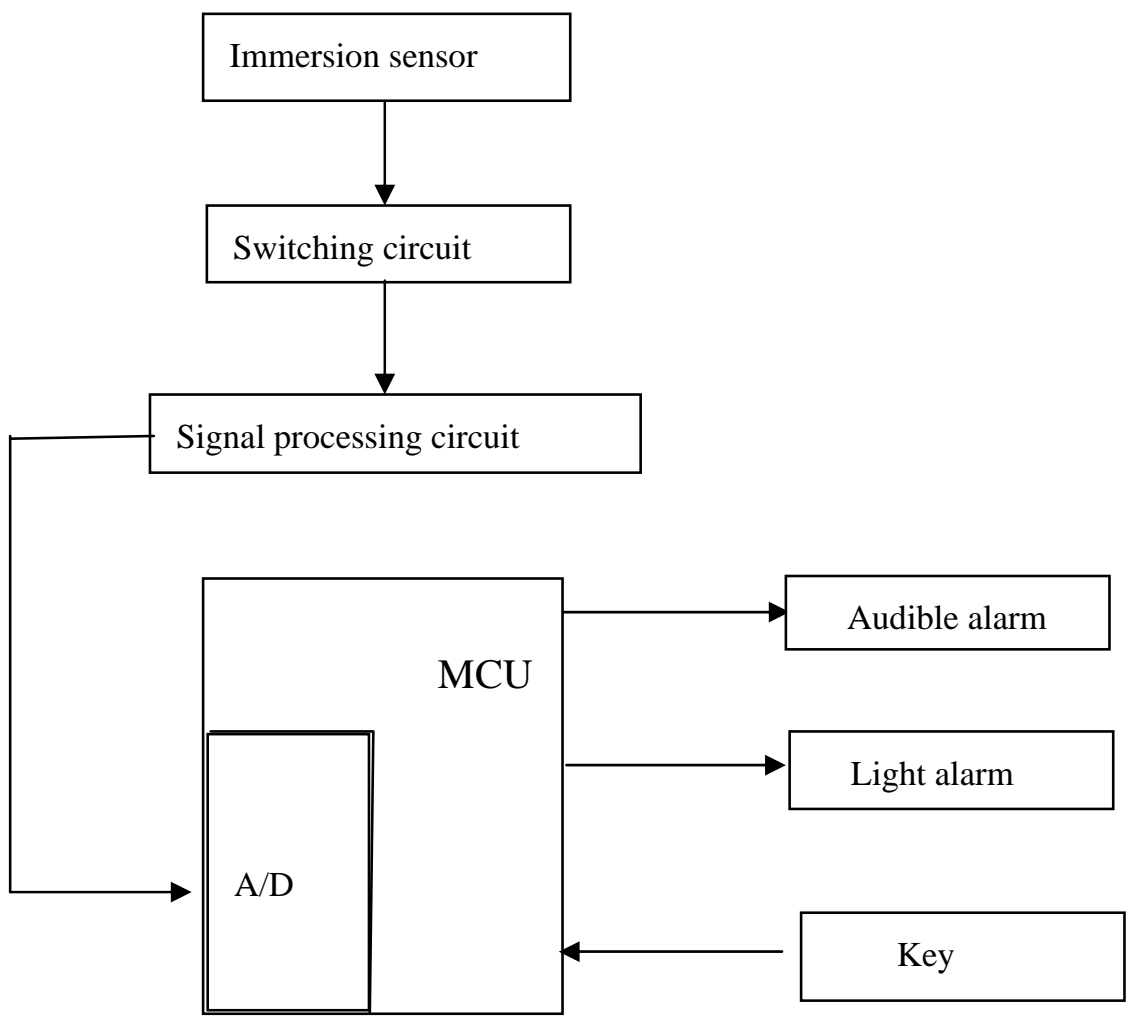

Figure 1 system block diagram

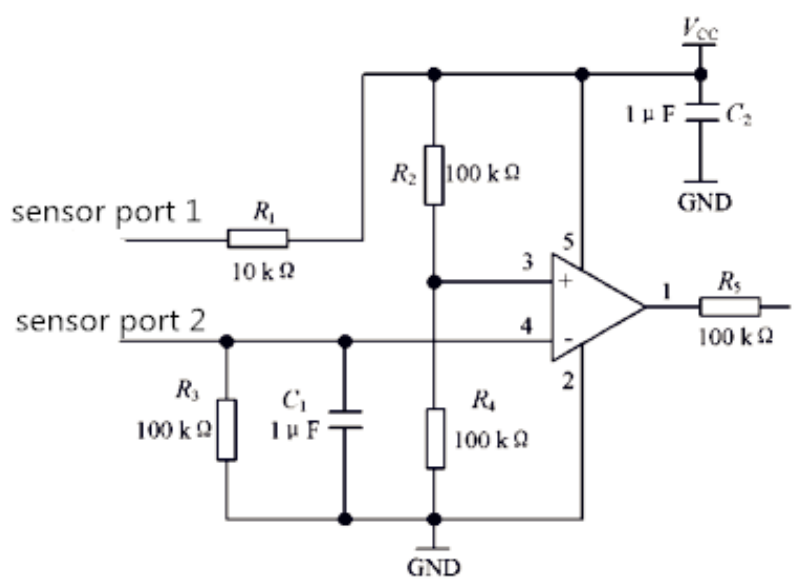

Figure 2 water immersion sensor detection circuit

Through the input channel multiplexing P1.0-P1.7 pin of ADC module MCU built-in STC12C5A60S2, users can set up 8 road in the middle of any settings for the ADC function by the software, the reference voltage of ADC module is MCU power supply voltage. The system uses 16 analog switch CD4067 to connect the sensor output and mcu.

Power supply circuit. The task of the power supply circuit is to provide the power for the MCU, to filter out the interference of the external environment at the same time, and to 
stabilize the voltage and avoid the change of the external environment. This part of the function is realized by the voltage regulator integrated circuit and the filter capacitor.

Figure 3 shows a typical circuit of the power supply circuit.

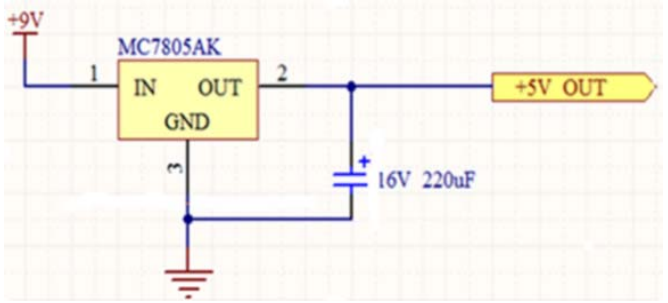

Figure 3 power supply circuit diagram

Acousto-optic alarm circuit. The type of buzzer is active buzzer, the internal device of the utility model is integrated with multi harmonic oscillator, if DC is applied in the external it can work normally, its control circuit and driving circuit are very simple and convenient. At the same time, the light emitting diode is driven to light the diode when the water leakage is detected.

The LED lamp circuit is shown in Figure 4, the buzzer and the drive circuit are shown in figure 5 .

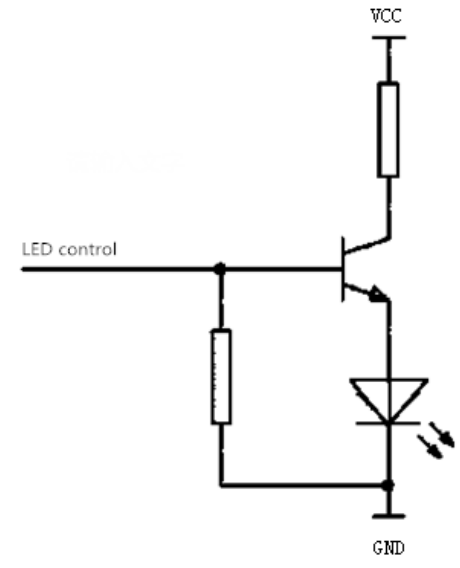

Figure 4 LED lamp circuit diagram.

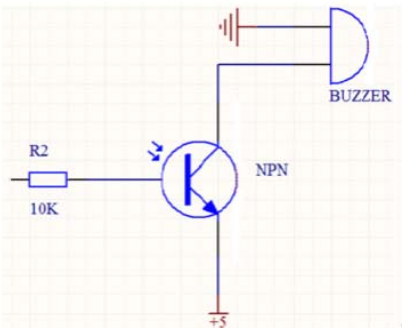

Figure 5 buzzer circuit

\section{System software design}

Software system uses the method of full range sequential scanning program and real-time monitoring of the working state of the water sensor electrode. If the electrode water sensor is abnormal, it will open the sound alarm and light alarm. In the test room, the controller through the numbered LED lights can determine which compartment in the end of water leakage, then to confirm whether there is water leakage, and then take emergency measures. The software design flow chart is shown in figure 6 . 


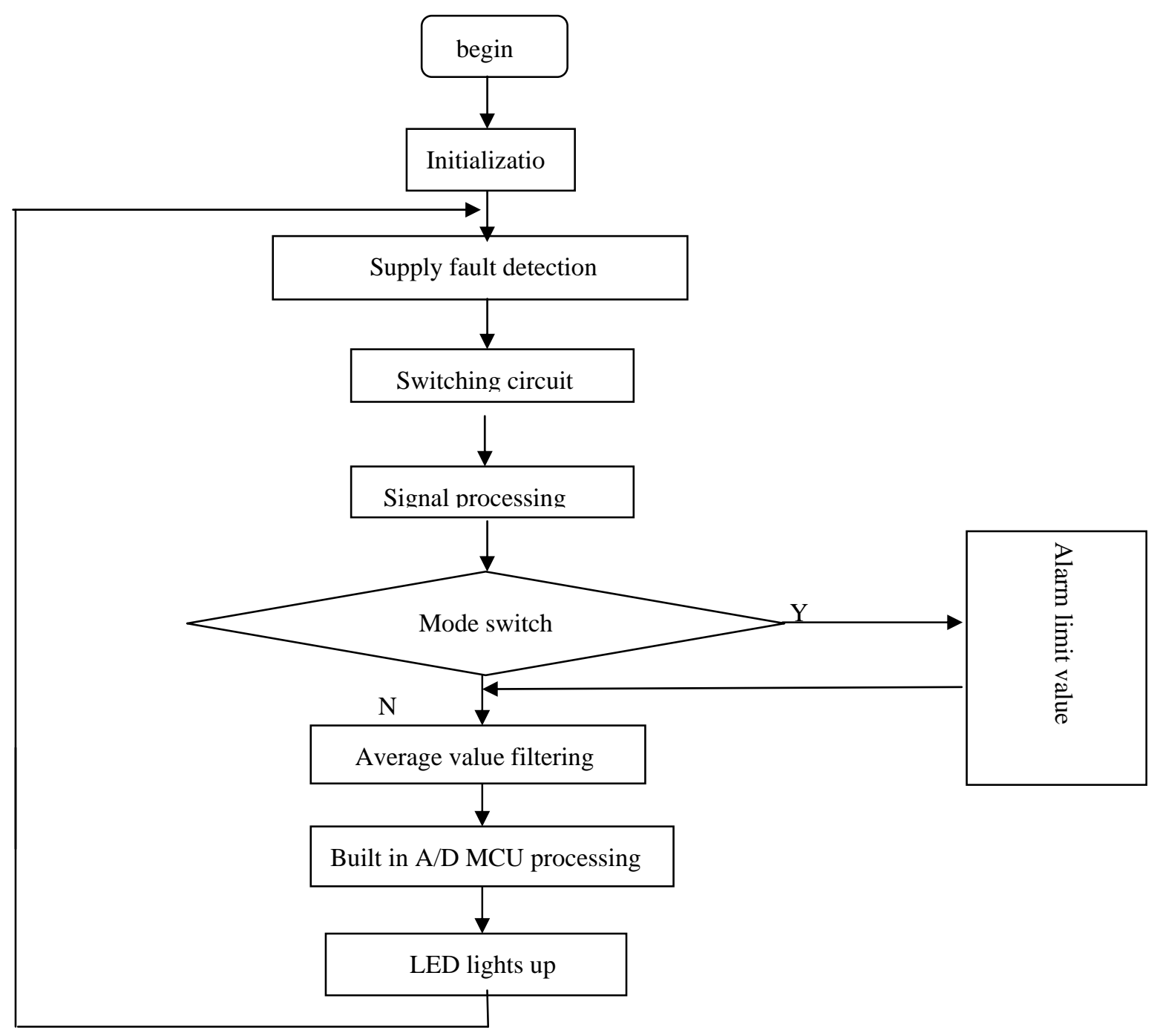

Figure 6 software design flow chart

\section{Conclusion}

Cabin leakage is a common and serious accident when the ship is sailing. In order to prevent the accident from happening in the bud, the paper designs a sound and light alarm system. The electrode type water immersion sensor is used to combine the water leakage detection and alarm. When the ship is leaking, the sound and light alarm is carried out by a single chip microcomputer, so as to play an early warning role to the danger.

\section{Reference}

[1] Murakami Akitsugu, Kinouchi Yohsuke, Akutagawa Masatake et al..Web-based integrated alarm monitoring system in the ICU.[J].Conference proceedings : ... Annual International Conference of the IEEE Engineering in Medicine and Biology Society. 2007, 6.

[2] Koch Sven, Sheeren Amanda, Staggers Nancy. Using personas and prototypes to define nurses' requirements for a novel patient monitoring display.[J].Studies in health technology and informatics, 2009, 146. 
[3] White L J, Jackson F, McMullen M J et al..Continuous core temperature monitoring of search and rescue divers during extreme conditions.[J]. Prehospital emergency care : official journal of the National Association of EMS Physicians and the National Association of State EMS Directors, 1998, 2(4).

[4] Witt Matthew J, Godley Brendan J.A step towards seascape scale conservation: using vessel monitoring systems (VMS) to map fishing activity.[J].PL o S One, 2007, 2(10).

[5] He David Da, Winokur Eric S, Heldt Thomas et al..The ear as a location for wearable vital signs monitoring.[J].Conference proceedings : ... Annual International Conference of the IEEE Engineering in Medicine and Biology Society. IEEE Engineering in Medicine and Biology Society. Conference, 2010. 